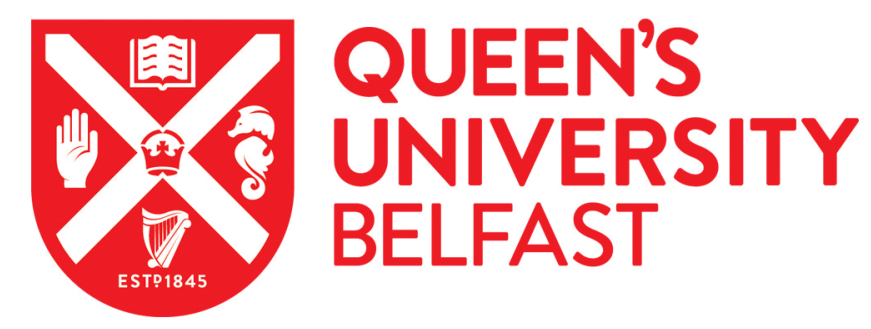

\title{
How can tomorrow's doctors be more caring? A phenomenological investigation
}

Gillespie, H., Kelly, M., Gormley, G., King, N., Gilliland, D., \& Dornan, T. (2018). How can tomorrow's doctors be more caring? A phenomenological investigation. Medical Education, 52(10), 1052-1063.

https://doi.org/10.1111/medu.13684

Published in:

Medical Education

Document Version:

Peer reviewed version

Queen's University Belfast - Research Portal:

Link to publication record in Queen's University Belfast Research Portal

Publisher rights

(c) 2018 John Wiley \& Sons Ltd and The Association for the Study of Medical Education. This work is made available online in accordance with the publisher's policies. Please refer to any applicable terms of use of the publisher.

\section{General rights}

Copyright for the publications made accessible via the Queen's University Belfast Research Portal is retained by the author(s) and / or other copyright owners and it is a condition of accessing these publications that users recognise and abide by the legal requirements associated with these rights.

Take down policy

The Research Portal is Queen's institutional repository that provides access to Queen's research output. Every effort has been made to ensure that content in the Research Portal does not infringe any person's rights, or applicable UK laws. If you discover content in the Research Portal that you believe breaches copyright or violates any law, please contact openaccess@qub.ac.uk. 
How can tomorrow's doctors be more caring? Phenomenological investigation

4

5

6 


\section{Abstract}

2 Background: Peabody's phrase 'the secret of the care of the patient is in caring for the patient'

3 inspired generations of doctors to relate humanely to patients. Since then, phrases like

4 'managed care', have impersonalised caring. The term 'patient-centred' was introduced to re-

5 personalise caring. Ironically, though, professionals' preconceptions rather than patients'

6 experiences have defined these terms. Using patients' experiences of doctors being (un)caring

7 to guide doctors' learning could re-invigorate caring. Interpretive phenomenology provides

8 qualitative research tools to do that.

9 Methods: Ten patients, purposively selected to have broad experiences of primary, secondary,

10 and/or tertiary healthcare, consented to participate. To stay close to their lived experiences,

11 participants first drew 'Pictor' diagrams to represent relationships between them and

12 professionals during remembered experiences of (un)caring. A researcher then used the

13 depictions to structure in depth, one-to-one explorations of the lived experience of caring.

14 Verbatim transcripts were analysed using Template Method. To remain very close to patients' experiences, the researchers assembled a narrative description of the phenomenon of caring using participants' own words.

17 Results: Caring doctors were genuine. They allowed their own individuality to interact with patients' individuality. This made participants feel recognized as individuals, not just diseases.

19 Caring doctors listened and spoke carefully, encouraged expressions of emotion, were

20 accessible and responsive, and formed relationships. This empowered participants to be

21 actively involved in their own care. Little things like smiling, shaking hands, admitting

22 uncertainty, asking a colleague for advice, and calling a participant unexpectedly at home

23 showed that doctors were prepared to 'go above and beyond'. This was caring.

24 Conclusion: These findings provide medical educators with an interpretation of caring that is

25 truly patient-centred. Coupling technical proficiency with human qualities - being genuinely empathic and respectful - within doctor-patient relationships is the essence of caring. 


\section{Introduction}

2 "I shall not today attempt further to define the kinds of material I understand to be embraced 3 within that shorthand description ... and perhaps I could never succeed in intelligibly doing so.

\section{But I know it when I see it"}

US Supreme Court Judgement by Justice Potter Stewart, 1964

Peabody's seminal article entitled 'The Care of the Patient', published in 1927, took it as axiomatic that doctors should 'care' for patients. (1) Caring was, however, so indefinable that

Peabody used a tautology - 'the secret of the care of the patient is in caring for the patient' - to capture it. He knew a lot about caring, emotionally as well as practically, because he cared for sick people whilst, himself, receiving care for life-limiting disease. Peabody's aphorism has become a canon of medical education expressing the sentiment that medicine is a humane practice, which exists within relationships between doctors and patients, and is founded on values.

\section{Medicine had become so much more sophisticated by 1969 that psychotherapist Enid} Balint found it necessary to define the caring role of doctors as understanding unique human beings within therapeutic relationships; she coined the term 'patient-centred medicine' to express this. (2) By the 1980s, healthcare had become yet more complex and fragmented. The influential Picker Institute responded with a call to arms for doctors to focus on patients and their families rather than just treat diseases.(3) They termed this 'patient-centred care'. A literature review published in 2000 identified five conceptual dimensions along which clinicians could focus their efforts to be patient-centred: taking a biopsychosocial perspective; seeing patients as people; sharing power and responsibility; forming therapeutic alliances; and doctors also being people.(4) Soon afterwards, a landmark report published by the Institute of Medicine report (5) defined patient-centred care as being 'respectful of and responsive to individual patient preferences, needs, and values, and ensuring that patients' values guide all clinical decisions.' There were now precise definitions for what had, in earlier times, been 
regarded as indefinable.

2 This drive to define the caring qualities of doctors was, it has been suggested, a reaction to

3 the increasing technical complexity of medicine. (6) Sennett (7) described this as 'Fordism',

4 after Henry Ford who revolutionised automobile manufacturing by inventing the production

5 line. The increasing complexity of medicine required doctors to have increasing numbers of

6 components, of which patient-centredness was one. Those components had to be quality

7 assured, by reliable assessments. For doctors' humane qualities to be assessable, they had to

8 be defined. Hodges graphically described the unintended consequences of the production line

9 that resulted: "I observed a student, who had trained for many weeks in a communication

10 programme, say to a real patient on the ward: 'Oh that must be hard for you... wow that must

11 be hard for you ... . oh, yes that must be really hard for you', until the patient, frustrated by the

12 shower of 'empathic comments' that were obscuring a discussion of her symptoms said, 'Can

13 you stop saying how difficult this is? This interview is difficult!'”.(8) What Hodges described is a

14 type of patient-centredness that fulfils the letter of the law by commoditising empathy whilst

15 paying scant attention to patients' real needs. Experiences of this kind led influential authors

16 to re-emphasise that humane care resides in relationships between doctors and patients

17 rather than being 'patient-centred'. (6) Interestingly, these authors described relationship-

18 centred care as having multiple dimensions rather than being precisely definable. (6)

19 Reporting a comprehensive literature review of caring,(9) we noted that professionals have

20 been readier to define caring themselves than explore patients' unique experiences of it. Most

21 publications have come from nursing research and very few from medical education

22 research.(9) That literature review and the articles we review here lead us to summarise the

23 'state of the art' of caring thus: Caring is a relational phenomenon. It is central to medical

24 practice. Despite the avowed importance of caring, doctors need constantly to be reminded it

25 is a broader and more complex phenomenon than treating disease. Doctors and patients know

26 caring when they experience it but attempts to promote caring by defining it have had 
1 unintended, adverse consequences. Despite arguments that caring should be patient-centred,

2 professionals have more often done so on patients' behalf than ask them what caring is. This

3 poses basic questions. Should researchers go to greater lengths to define caring? Or should

4 they regard caring as something that is indefinable, which doctors and patients recognise

5 when they experience it? If the latter, how can caring be investigated and, even more to the

6 point, to whose experiences should investigators pay most attention?

7 This research assumes that caring is relational and that patients are the partners in caring

8 whose experiences should tell doctors, and those studying to be doctors, how to be more

9 caring. Edmund Husserl, father of contemporary phenomenonology, exhorted philosophers to

10 'return to the things (phenomena) themselves'. (10)Rather than defining caring, this research

11 'returned to the phenomenon of caring, itself, by asking: how do patients experience doctors

12 being (un)caring?

\section{Methods}

\section{Ethical Approval}

15 The Office of Research Ethics Committees XX (ORECXX) gave ethical approval for the study

16 (Approval no 15-NI-0172).

17 Conceptual orientation and methodology

18 Frustrated by the objective focus of empirical science, Husserl argued that it was possible to

19 set aside one's assumptions about everyday occurrences and get closer to the 'essence' of

20 human experience. So-called transcendental phenomenology explored the underlying

21 structure of individual experience (11) moving from the individual to the universal and bringing

22 one's assumptions to consciousness in order to set them aside ('bracketing'). Later

23 phenomenologists, notably Heidegger and Gadamer, doubted it was possible to bracket out

24 one's world-view. Rather, new understandings came from exploring one's subjectivity in

25 relation to a phenomenon of interest. This is termed interpretative (hermeneutic)

26 phenomenology; this explores the essence of phenomena by 'bringing them to presence', 
1 which makes them recognizable and 'true'.(12) From a phenomenological viewpoint,

2 researchers understand their topics of inquiry through 'inter-subjective' transactions between

3 their individual experiences and their relatedness to the subjects of their inquiries.

4 Hermeneutic inquiry enables researchers to explore things that are are habitual or taken-

5 for-granted and not, therefore, the subject of conscious reflection. Later sections explore

6 how we turned those philosophical principles into qualitative research practice using the Pictor

7 technique, template analysis, and team reflexivity.

$8 \quad$ Research team

9 Hermeneutic interpretation requires researchers to respond reflexively to research

10 subjects. We wanted to influence the clinical education community so we formed a team that

11 comprised a medical student $(X X)$, primary $(X X, X X$, and $X X)$ and secondary/tertiary care $(X X)$

12 medical practitioners, and a non-clinician with expertise in phenomenological psychology (XX).

13 The physicians are educators in medical schools in the UK and Canada. We were concerned

14 that power differentials between participants and doctors might inhibit participants and

15 addressed this by the most junior (and, we assumed, least intimidating) member of the

16 research team (XX, medical student) to interview participants.

$17 \quad$ Setting

18 Participants were recruited in two general practices (one urban, one rural) in XX, UK.

19 General practitioners (GPs - family physicians) provide acute and chronic care longitudinally

20 over the course of patients' lives and coordinate the provision of community and hospital

21 services. Recruiting in primary care allowed us to identify patients whose cumulated

22 healthcare experiences spanned primary, secondary, and tertiary care.

23 Sampling and recruitment

24 Any adult patients who had any experience of care, spoke good English, and was booked to 25 see a GP within the 12-week study timeframe was eligible. Phenomenological research

26 typically recruits small samples of participants (often no more than ten people). In order that a 
1 small number of participants could represent a wide spectrum of healthcare experience, the

2 GP researchers identified potential participants attending upcoming clinics from records and

3 personal knowledge. UK research ethics approval requires a 'cooling off' period of at least 24

4 hours between participants receiving a full explanation of the study and giving consent to

5 participate. Whilst $X X$ and $X X$ started the process of recruitment, $X X$ (medical student)

6 completed it to minimise coercion and bias towards reporting positive experiences. Further, XX

7 explained that transcripts would remain anonymous, the GPs who had recruited participants

8 would not see interview transcripts, and we were as interested in negative as positive

9 experiences.

$10 \quad$ Data collection

11 The goal of interpretive phenomenology is to elicit descriptions of participants' lived

12 experiences rather than their ideas. In earlier research, patients found it hard to describe

13 healthcare experiences because circumstances changed quickly during these and many

14 agencies were involved. (13) A range of visual mapping techniques have been used to

15 overcome this problem, notably the Pictor technique, (14) which was developed specifically to

16 help participants in experiential research, including phenomenology, to describe their

17 experiences of complex relationships. (13) Derived from a technique used in family therapy

18 (15) and later adapted for education research, Pictor has been used in the context of medical

19 education (16)(17), nursing(18), midwifery (19), and end-of-life care(13). It was deliberately

20 designed to be simple, so participants could speak freely about bewildering experiences. Pictor

21 is not an end in itself. It provides visual hooks, which allow researchers to ask questions that

22 help participants give richer accounts of lived experiences than they might otherwise be able

23 to do.

24 In one-to-one interviews, XX asked participants to recall an experience of caring. This could

25 be positive or negative, in any setting, with any healthcare professional. XX asked participants

26 to identify important elements of these experiences and write them on large, coloured, arrow- 
1 shaped pieces of paper. These elements included features of the people, how those people

2 treated participants, the settings, and anything else that was significant. Having briefed them,

3 she left participants alone to represent their chosen experiences by writing pseudonyms or

4 role titles on the arrows and position them on a large sheet of paper. Figure 1 shows an

5 example of a Pictor Chart. These provided a loose structure for the interviews. Questions

6 about why arrows had been placed close together, or pointing in particular directions, or

7 whatever else the charts displayed cued participants to recount their experiences whilst

8 remaining within their experiences rather than the researchers' preconceptions. Because

9 questions were directed to the chart rather than the person, it was possible for interviews be

10 less interrogative, intimidating, or conducive to positive reporting bias than using conventional

11 elicitation techniques. Interviews lasted 45-70 minutes. XX photographed each Pictor Chart

12 and marked the positions of the coloured notes to create a permanent record. Whilst the

13 charts stimulated discussion, it was the interviews rather than the charts that provided data

14 for further analysis. XX recorded all interviews and transcribed them verbatim.

FIGURE 1 AROUND HERE

$18 \quad$ Analysis

19 Just as there are many, sometimes competing, lines of thought in phenomenological

20 philosophy, so there are differing views about whether it is more appropriate to present

21 participants' narratives idiographically or assemble them into themes that are common to

22 more than one participant. The purpose of this research - to help medical students and the

23 busy practitioners who teach them learn more about the lived experience of caring - guided us

24 to synthesise an interpretation from the dataset as a whole. As other phenomenologists have

25 described this, our goal was 'not to describe .. participants fully, nor to conserve their stories

26 and experiences intact, but rather to .. expand (the medical education community's) 
1 understanding of the phenomenon we (were) attending to.' (12) We did not intend to 'report

2 on meaning but create it' and, by carefully attending to, 'selecting, and crafting participant

3 contributions,' to 'stand enriched beyond the initial horizons of either the researcher or the

4 participant'. (12) Template method (20) structured a back and forth movement between

5 participants' reported experiences and our interpretation (the 'hermeneutic circle'). This was

6 designed for psychology research, where interpretations are expected to be tightly aligned

7 with data.

8 The analysis had several components, which together produced a rich and detailed

9 description of patients' experiences. $X X$ and $Y Y$ read all transcripts in their entirety, identified

10 preliminary themes, then developed an initial analytical template. They then independently

11 open-coded a single transcript by highlighting all sections of text that appeared relevant to the

12 research question. They clustered these codes to revise the initial template. They repeated this

13 open, descriptive coding on five randomly selected transcripts. They extracted descriptive

14 codes, and grouped ones that shared meaning to form higher-level interpretive codes. They

15 grouped these codes into themes. They then applied this revised template to the remaining

16 transcripts and further refined it as needed. Table 1 shows how the template evolved.

TABLE 1 AROUND HERE

The validity of hermeneutic research is to be judged partly by whether interpretations that emerge 'ring true' to others; 'our capacity to recognize ourselves in the .. story of human existence which is recounted there'. (21) To avoid any one perspective dominating, and to remain aware of their individual perspectives, team members scrutinised the evolving

24 interpretation, challenged it, and discussed points of disagreement. As the researchers

25 collectively interpreted the data, they compared their evolving understanding of patients'

26 experiences to their individual clinical and educational experiences. Other team members

27 encouraged $\mathrm{XX}$ to articulate her experiences, as a medical student starting the clinical phase of 
1 her programme, alongside their own experiences. They encouraged $X X$ to draw other team

2 members' attention to issues of power and hierarchy that may have affected the findings. The

3 researchers ensured the emerging interpretation was grounded in participants' experiences,

4 and not their professional experiences, by regularly referring back to the whole transcripts.

5 They continued collecting data until analysis suggested the sample was sufficient to support a

6 rich interpretation of patients' experiences of caring.

\section{Presentation of results}

9 Although the interview prompts allowed participants to talk about caring experiences with

10 professionals other than doctors, most spoke just about doctors so we have used the noun

11 'doctor' throughout. For brevity, we have used the phrase 'caring was ...' as a shorthand for

12 'participants experienced caring when doctors were ....'. We wove together the narrative of

13 results out of words participants used in their individual stories for two reasons. First, because

14 this stayed closer to participants' experiences than paraphrasing their words; and second

15 because we thought it was more likely these would 'ring true' to the doctors and medical

16 students we hoped to influence in a way that a more abstract presentation of findings would

17 not. (22) For readers to link quotations with participants, without disrupting the narrative flow,

18 we have linked longer quotations to participants using superscript numbers. For example, ${ }^{\mathrm{A}}$

19 refers to a quotation from Participant A. Other phenomenologists have argued that there is no

20 obligation to link individual participants to every quotation because 'it matters less who it

21 came from than what it has to say about the topic'. (12) The interpretation of the topic, from

22 this stance, is of greater relevant to educators and students than the research participants,

23 whose contribution was to 'generate insight derived from their unique knowledge and

24 contributions.' (12) We have, however, prefaced the results with one longer excerpt in

25 vernacular (Northern Irish) English. We are willing to provide others on request. 


\section{Results}

2 Ten participants, whose demographic details are summarised in Table 2, described a variety

3 of experiences during acute and chronic illnesses in community and hospital settings. After a

4 rich excerpt from one participant, we present the main, unifying finding, and then three

5 subthemes.

You know I kind of owe my life to them, the ambulance men and these two professors. You see, I was out for the world when all this was going on, and they kept me alive to this day Prof Y would say to me, because I still attend him, that they often talk about me. They are just very, very nice gentlemen. Prof $X$ you couldn't just get any nicer than him, he's a very soft natured person, he has a nice, nice smile on his face, he never looks gloomy or

11 down. And, the way he acts, even if you're sitting in the waiting room you see him bringing a little old lady out of his room after seeing her, and he takes her right round to the room to

13 get her bloods done. Seeing things like that in him, he's just really caring. And he makes you

14 feel you are important in your visit with him. It's just wee things, like when you go in and he shakes your hand and tells you to sit down, and no, I think he just listens to you. He gives you time to explain what's going on ... He's an expert in his field, so that makes you safe and

17 makes you feel good, that you're seeing a professor. He knows everything about it but he

18 also knows about me. I've met many a consultant and different doctor who is just as caring

19 and nice. I think it's just their facial expressions, and, the way they speak to you and with

20 you. Like they speak in a nice manner, and speak so you can understand. They are not all

21 gibberish medical terms and say it in a way that you can understand it. Participant 6

TABLE 2 AROUND HERE 
1 be alright". It was "real empathy, real engagement with an individual on their level".

2 Participants found this genuineness hard to describe. They “couldn't just rattle off things; it's

3 just a comfort level and ... little things you experience as you're with a doctor (that) ... decide it

$4 \quad$...". ${ }^{\text {A }}$ Caring doctors didn't "even have to think about going the extra mile, it just comes natural

5 to them". Being knowledgeable contributed to genuine caring: "it's their knowledge ... they

6 have studied this to get their knowledge, to care for you ... knowing that knowledge alone

7 makes you caring." F Being genuine had three distinct facets. Caring doctors: allowed their own

8 individuality to interact with patients' individuality; engaged with participants to form

9 relationships and communicate; and did little things that went above and beyond.

$10 \quad$ Individuality

11 Genuine caring was "... about assessing the individual. And engaging with the individual at

12 their level." It was recognising "that every individual is completely different." This inspired

13 confidence: "They (doctors) have a better chance of getting it right because they are showing

14 genuine interest in you; you're not just a number and another box to tick". ${ }^{\circ}$ Caring was when

15 "they asked about you as, not a patient, but it was you they were interested in - they weren't

16 here just to sew you up or, you know, get rid of you or the infection, it wasn't all about that". ${ }^{6}$

17 Caring doctors saw "that the person in front of them is not just a heart, or a surgical case ... but

18 is instead a human being". ' They recognised and embraced the personal element of practice;

19 "it's just that he kind of really, really knows what's going on with me...".

20 Caring doctors were interested in more than participants' illnesses: "He knows everything

21 about it (the illness) but he also knows about me." "When I go into the GP, its 'how's things?

22 how's it going? are you still working?'". Caring doctors were "interested in the whole family

23 aspect as well". Caring doctors made participants feel "as if you were the only one there who

24 she was caring for". They remembered important details; and gave patients a feeling "that

25 despite all the hundreds of people they see, that they have actually locked away a bit of

26 information about you." ${ }^{G}$ 


\section{Engagement}

$2 \quad$ Caring doctors engaged participants by forming relationships. They were "always

3 interested". They "made contact with (participants), looked at them, talked to them, listened

4 to them, asked them about their fears and their apprehensions or whatever". ' They

5 empowered participants to be actively involved in their own care by asking "what the patient

6 thinks, because they will have an opinion". They invited participants to share in decision

7 making. Caring doctors involved participants' families by saying "look go home and talk it over

8 with the wife". They gave balanced information and didn't "put the scare tactic into you."

9 Caring doctors took participants seriously and were not dismissive, unlike doctors whose

10 "attitude was 'uhum, right, sure' as they were writing the prescription." Caring doctors were

11 responsive; "he interacted with me, at my level ... he treated me like a sentient, sensible,

12 intelligent woman ... looking at a situation and him recognising what his responses and

13 reactions needed to be, he wasn't dismissive, he was engaged". ${ }^{\mathrm{E}}$

14 These relationships lasted over time. Caring doctors made themselves accessible: "I think even still if I lifted the phone and just said I was ill he would help". They offered follow-up care, which made participants feel safe; "you know, we mightn't come back, but you know that you could". "They still take an interest in me 12 years later ... that's just one real good experience of caring, and ... it still continues ...". F Time fostered caring: "The longer you know someone, the more you care about them. You know, so it's all about getting to know someone". ${ }^{6}$ Time made caring relationships resemble friendships: "when you come in, he sort of smiles at you

21 and you sit down, and you sort of feel that you're coming to see, well, a friend." ' Caring relationships were, inevitably, constrained. In primary care: "General practice has changed, 23 and the chance of you seeing the same doctor every time is remote." J In secondary care: “...

24 you're in and out of there so you don't really have personal time with the doctor like you 25 would coming into the GP"; "I was aware that this man was going to cut me open and I had 26 never set eyes on him before" ${ }^{10}$ But those constraints did not preclude caring. 
$1 \quad$ Caring communication formed caring relationships: "They speak in a nice manner and speak

2 so you can understand". Caring doctors did not use "gibberish medical terms", but spoke "in a

3 way that you can understand". They communicated thoughtfully: "no matter how unpalatable,

4 you would say it the way you want to be told it ... you have to think about how the other

5 person is receiving this information". ${ }^{G}$ They legitimised participants' concerns; "... it was the

6 fact that someone else recognised that...at least he knows ... I'm not making it up".

7 Caring doctors listened carefully and provided space for participants to express emotions:

8 "They just seem to listen ... you can go in and open up to them... I can just come in here and

9 cry, and the doctor listens, and you can let it all out." ${ }^{8}$ They also listened to what participants

10 didn't say: "It was somebody who had twigged something about me... I was anxious ... it

11 wasn't just to do with the fact I had a particularly nasty illness. And therefore, he was reacting

12 to me as a human being".

13 Caring communication was not limited to consultations. It included being welcomed and 14 updated on waiting times and test results: “...sometimes you all have to rush. But even if you're 15 walking past, saying 'You ok there? It won't be long till were getting looking at you' ... that's 16 about caring". ${ }^{\text {B }}$

17 Caring doctors responded to differences between individuals; "It needs to be calibrated to

18 different patients. Different patients respond on different levels". Participants responded by

19 responding to doctors' individuality, including their imperfections: "at the end of the day ...

20 they are human like everybody else. You know, we all have good days and bad days". ${ }^{\mathrm{D}}$ This

21 allowed doctors to be special: "I had seen a few other doctors here and I wasn't until I had

22 seen $\operatorname{Dr} \mathrm{X}$ that I realised ... 'I want him'”. A

23 Little things that went above and beyond

24 Going above and beyond was "very simple wee things" that "make all the difference".

25 Smiling, being welcoming, and shaking hands meant that "from when you walk in the door,

26 you know that somebody is going to care for you." Little words as well as little gestures were 
1 caring: participants "could hear by the questions that he asked me that he knew what he was

2 talking about". ${ }^{D}$ And little acts: "There's one in particular who, every time she takes blood, I

3 never bruise". Little things reassured participants: "It was just when I walked in here, in

4 through the door ... he was cool, calm and collected ... it was just reassuring that he was doing

5 the right thing". ${ }^{A}$ Competence was necessary for caring but not, of itself, sufficient: "There is

6 no point in having someone who is really nice but hasn't a clue what they are doing ... but

7 provided that you're academically sound, I think you need both things." ' Caring doctors did

8 not necessarily have the right answer all the time: "they might go and ask another doctor's

9 opinion on it ... they are humble enough that they can do that". F Little things added up to

10 caring: "it wasn't specific things that he said or done, it was the whole approach". Particular

11 acts, albeit little ones, could be caring too: "for a doctor to phone you at tea-time, that's what

12 struck me. Doctors don't normally take the time to do that." A

\section{Discussion}

15 The essence of caring, as experienced by participants in this study, was to be genuine.

16 Doctors showed genuineness by relating to patients as individual human beings (not as

17 diseases), engaging with them, and doing 'little things that went above and beyond'. Caring

18 was not determined either by doctors' technical ability to treat disease or to behave

19 empathically. Caring comprised both. Participants experienced caring within relationships that

20 conformed to the four principles of relationship-centred care. (3) These included: sharing

21 doctors' personhood rather than just fulfilling roles; acknowledging patients' affects and

22 emotions; having truly reciprocal relationships rather than delivering care; and building

23 relationships on moral foundations. As well as forming relationships with patients, caring

24 doctors conformed to other important dimensions of patient-centred care by having good

25 relationships with other doctors and non-medical professionals and with the communities of

26 which they and patients were part. 

... respond to the patient by his (sic) interpretations and theories.' Doctors, they argued,

3 should develop awareness of how they responded to patients. It would have been hard, we suggest, for doctors to have been caring in the ways participants described without that sensibility. The principles of relationship-centred care suggest it would have been hard to maintain that stance towards patients without having self-awareness, and a capacity to create and sustain personal integration. (6) The close analogy between our findings and the principles of relationship-centred care suggests that caring doctors had what has been described as 'clinician-self relationships'.

10 Doctors often present competence and care as a binary, at odds with each other. (23)

11 Ninety years ago, Peabody (1) argued against this: 'The art and science of medicine

12 [healthcare] are not antagonistic but complementary. There is no more contradiction between 13 the science of medicine and the art of medicine than between the science of aeronautics and 14 the art of flying'. Like patients reported elsewhere, participants in our study expected 15 clinicians to be both competent and caring (24)(25) because 'compassion without competence 16 is a meaningless, if not harmful intrusion in the life of a person needing help'. (26) Caring

17 builds on competence. Doctors who went 'above and beyond' the basic expectation of competence carried out small acts of kindness that, as previously reported, transformed competence into caring. (27)

20 Our participants described how caring exists in the eye of the beholder. In earlier research,

21 (23) some patients rated video recordings of professionals' behaviour as caring whilst others

22 rated the same behaviour as uncaring. The author concluded that caring was being aware of

23 patients' perspectives and attending to verbal, nonverbal, and emotional cues rather than

24 exhibiting a set of predefined behaviours or attitudes. Our findings extend these findings.

25 Establishing genuine relationships, where individuals are welcomed as people with real-lives,

26 families and pressures, rather than problematic bodies, gives behaviours meaning. This is 
1 borne out by research into women's experience of caring during labour, which showed how

2 trusting relationships, where each woman was treated as an individual in her own right,

3 individualised caring experiences. (28) Patients receiving cancer care were more concerned

4 about care processes and therapeutic relationships than symptom control, which clinicians

5 viewed as paramount. (29)

$6 \quad$ Limitations

7 Our sampling and interviewing strategy limits the transferability of our findings. The

8 research context has an ethnically homogenous population yet participants from different

9 cultural backgrounds may have different experiences of caring. Whilst we recruited a varied

10 sample of participants, whose experiences covered a wide range of contexts of care,

11 conducting our recruitment in general practice gave the research an inescapably primary care

12 emphasis. Recruitment by doctors who cared for patients may have introduced a social

13 desirability bias, despite a third party having conducted the interviews. It is possible the

14 recruiting doctors unconsciously selected participants who were more likely to report positive

15 experiences of caring. Conducting Interviews away from home during business hours may have

16 prevented patients with occupational or caring responsibilities from participating in the study

17 and deterred others who did not want to attend healthcare premises.

18 Implications

19 It has been said that 'if the successful diagnosis and treatment of patients depends on the

20 establishment of intimate personal contact, (students) must be given opportunities to build up

21 the same type of personal relationship with patients'. (1) Communication training, when it

22 consists only of brief encounters with simulated patients, cannot do this. There is a risk that

23 brief, simulated encounters that contribute to summative assessments will promote

24 stereotyped behaviours, as described in Introduction, rather than relationship-centred care.

25 This may falsely reassure learners and teachers, reinforce a hidden curriculum of objectivity,

26 and promote the display of caring acts rather than genuine caring. One implication, therefore, 
1 is that curriculum leaders should seek balanced opportunities for students to develop caring

2 relationships alongside clinical competence. A second implication is that, if relationships are to

3 be genuine, educators need to develop their own emotional responsiveness in order to model

4 and support learning.

5 Another important implication is that healthcare students need to learn how caring is at

6 once complex and simple. It is complex because caring cannot be standardised or reduced to a

7 single behaviour. Yet, it is simple because caring is expressed in such small things as making

8 eye contact, standing up and greeting a patient, picking up on silences, and acknowledging

9 patients' feelings. Of course, these skills require genuine sensitivity; patients will quickly

10 discern if a doctor or student's behaviour lacks that sensitivity. Patient-centred communication

11 skills training, however, tends to focus on verbal communication and ignore the $60-90 \%$ of

12 communication that is nonverbal. (30)

13 We urge curriculum leaders and teachers to emphasise the importance of basic relational

14 skills, alongside all the paraphernalia of contemporary technical medicine. Training, and

15 testing the relational skills of the small minority of students who are not genuine and care little

16 for patients' wellbeing will likely be a fruitless task. For the majority who entered medicine

17 because they care about patients' wellbeing, we suggest that curriculum leaders should give

18 'little things' as much emphasis as technical medical interventions. They should repeat

19 relentlessly that neither competence nor caring is, alone, sufficient. Both are necessary, and

20 integrating the two into a genuinely caring medical identity should be every (student) doctor's

21 aspiration.

22 Conclusion

23 To conclude, patients' experiences show that doctors are caring when they allow their own

24 individuality to interact with patients' individuality, engage with patients, and do little things

25 that go above and beyond. Being genuine is the essence of caring. 


\section{Contributors}

2 There were no contributors other than the authors.

\section{Acknowledgments}

4 We thank Anneke van Enk for her constructive criticism and help revising the manuscript.

5

$6 \quad$ Funding

$7 \quad$ None

\section{Conflict of Interests}

9 The authors have no competing interests to declare.

\section{Ethical Approval}

11 The Office of Research Ethics Committees XX (OREC XX) gave ethical approval for the study

12 (Approval no 15-NI-0172).

13

14

15 


\section{References}

2 1. Peabody FW. The Care of the Patient. J Am Med Assoc. 1927;88:877-82.

3 2. Balint E. The possibilities of patient-centered medicine. J R Coll Gen Pract. $1969 ; 275(2): 152-6$.

5 3. Barry MJ, Edgman-Levitan S. Shared decision making - The pinnacle patient-centered care. N Engl J Med. 2012;366(9):780-1.

7 4. Mead N, Bower P. Patient-centredness: a conceptual framework and review of the empirical literature. Soc Sci Med. 2000;51(7):1087-110.

9 5. National Research Council. Crossing the quality chiasm: a new health system for the 10 21st century. Washington, DC, US; 2001.

11 6. Beach MC, Inui T, Frankel R, Hall J, Haidet P, Roter D, et al. Relationship-centered care: A constructive reframing. J Gen Intern Med. 2006;21(Suppl 1):S3-8.

13 7. Sennett R. The Craftsman. London: Allen Lane; 2008.

14 8. Hodges B. Medical education and the maintenance of incompetence. Med Teach. 2006;28(8):690-6.

16 9. Gillespie H, Kelly M, Duggan S, Dornan T. How do patients experience caring? Scoping review. Patient Educ Couns. 2017;100(9):1622-33.

18 10. Husserl E. Logical Investigations. 2nd ed. Moran D, editor. London: Routledge;

19 11. Langdridge D. Phenomenological psychology: Theory, research and methods. London: Pearson; 2007.

12. Moules N, McCaffrey G, Field J, Laing C. Conducting hermeneutic research: From philosophy to practice. New York: Peter Lang Publishing; 2015.

13. Hardy B, King N, Rodriguez A. The experiences of patients and carers in the daily management of care at the end of life. Int J Palliat Nurs. 2014;20(12):591-8. Health Res. 2013;23(8):1138-52. 
1 15. Hargreaves C. Constructs of Sociality and Individuality. In: Stringer P, Bannister D, editors. Constructs cof Sociality and Individuality. London: Academic Press; 1979.

3 16. Berkhout JJ, Helmich E, Teunissen PW, van der Vleuten CPM, Jaarsma ADC. How clinical medical students perceive others to influence their self-regulated learning. Med Educ. 2017;51(3):269-79.

17. van den Berg J, Verberg C, Scherpbier A, Jaarsma A, Lombarts K. Is being a medical educator a lonely business? The essence of social support. Med Educ. 2017;51(3):30215.

18. King N, Melvin J, Ashby J, Firth J. Community palliative care: role perception. Br J Community Nurs. 2010;15(2):91-8.

11 19. Bravington A. The Pictor Technique : Exploring Collaborative Working in Nursing. 2014;

12 20. King N. Doing Template Analysis. In: Symon G, Cassell H, editors. Qualitative Organizational Research: Core Methods and Current Challenges. London: Sage Publications; 2011. p. 453-78.

21. Caputo J. Radical hermeneutics: Repetition, deconstruction and the hermeneutic project. Bloomington, IN: Indiana University Press; 1987.

17 22. Crowther S, Ironside P, Spence D, Smythe L. Crafting Stories in Hermeneutic Phenomenology Research: A Methodological Device. Qual Health Res. 2017;27(6):82635.

23. Quirk M, Mazor K, Haley H, Philbin M, Fischer M, Sullivan K, et al. How patients perceive a doctor's caring attitude. Patient Educ Couns. 2008;72(3):359-66.

24. Halldórsdóttir S, Hamrin E. Caring and uncaring encounters within nursing and health care from the cancer patient's perspective. Cancer Nurs. 1997;20(2):120-8. About Cancer and Its Treatment for Quality Nursing Care. Oncol Nurs Forum. 2010;37(4):436-42. 
1 26. Roach M. The Human Act of Caring: A Blueprint for the Health Professions. Canadian Hospital Association; 1987. 53 p.

3 27. Greenfield BH, Anderson A, Cox B, Tanner MC. Meaning of caring to 7 novice physical therapists during their first year of clinical practice. Phys Ther. 2008;88(10):1154-66.

28. Berg M, Lundgren I, Hermansson E, Wahlberg V. Women's experience of the encounter with the midwife during childbirth. Midwifery. 1996;12(1):11-5.

7 29. Kendall M, Boyd K, Campbell C, Cormie P, Fife S, Thomas K, et al. How do people with cancer wish to be cared for in primary care? Serial discussion groups of patients and carers. Fam Pract. 2006;23:644-50.

10 30. Lorié Á, Reinero D, Phillips M, Zhang L, Riess H. Culture and nonverbal expressions of 11 empathy in clinical settings: A systematic review. Patient Educ Couns. 2016;100(3):41124. 


\section{$1 \quad$ Figure 1}

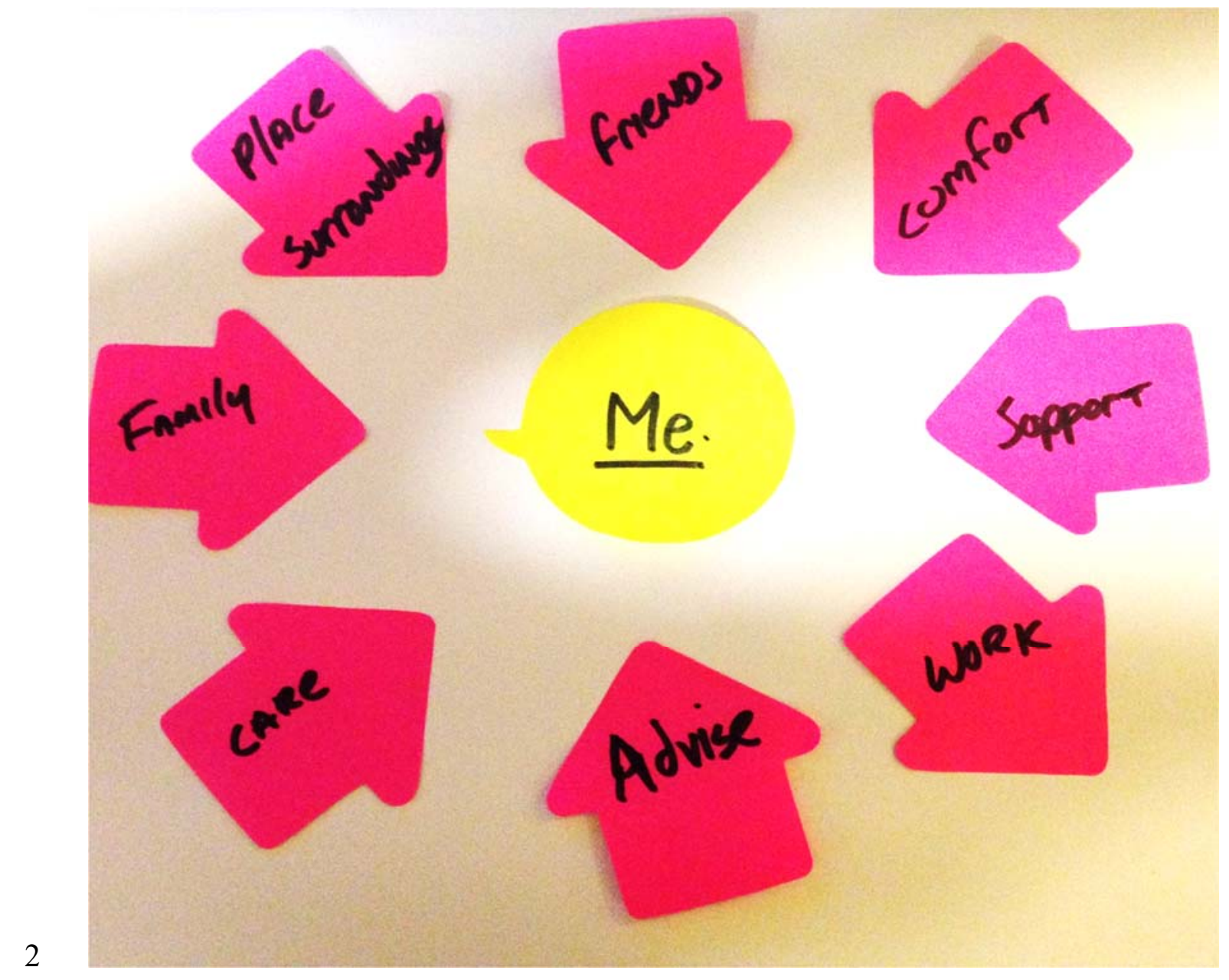

\section{$3 \quad$ Figure 1}

4 Example of a completed chart.

5 
Table 1

\begin{tabular}{|c|c|}
\hline Template 1 & $\begin{array}{l}\text { 1) Attributes } \\
\text { 2) Communication } \\
\text { 3) Relationships } \\
\text { 4) Management } \\
\text { 5) Present } \\
\text { 6) Limitations } \\
\text { 7) Small Things }\end{array}$ \\
\hline Template 2 & $\begin{array}{l}\text { 1) Goes above and beyond } \\
\text { (a) Presence } \\
\text { (b) Accessibility } \\
\text { (c) Patient not a burden } \\
\text { (d) More than just a job } \\
\text { 2) Personal Qualities } \\
\text { (a) Make patients feel certain ways } \\
\text { (b) Do certain things } \\
\text { (c) helpful / nice/ tolerant } \\
\text { 3) Treat patient as a person } \\
\text { a) Interested in patient } \\
\text { b) Not just a symptom } \\
\text { c) Accounts for social/family life } \\
\text { 4) Little things } \\
\text { 5) Competency } \\
\text { a) Efficient } \\
\text { b) Knowledgeable } \\
\text { c) Respond appropriately } \\
\text { d) Take patient seriously } \\
\text { 6)Relationship } \\
\text { a) Friendship } \\
\text { b) Continuity } \\
\text { 7) Limits of care } \\
\text { a) waiting times } \\
\text { b) HCPs are busy }\end{array}$ \\
\hline Template 3 & $\begin{array}{l}\text { 1) Care is individual } \\
\text { a. Patients are people } \\
\text { b. Patients are individuals } \\
\text { c. Doctors are individuals } \\
\text { 2) Caring doctors are competent } \\
\text { a. Diagnostic skills } \\
\text { b. Treat/ manage appropriately } \\
\text { c. Treat holistically and comprehensively }\end{array}$ \\
\hline
\end{tabular}




\begin{tabular}{|c|c|}
\hline & $\begin{array}{l}\text { d. Reflect on their own abilities } \\
\text { 3) Communicate } \\
\text { a. Engage with patients } \\
\text { b. Listen to patients } \\
\text { c. Ask appropriate questions } \\
\text { d. Act on patients' concerns } \\
\text { e. Engage with patients at their level } \\
\text { 4) Caring doctors form relationships } \\
\text { a. With patients } \\
\text { i. Ongoing or situational } \\
\text { ii. Quality } \\
\text { iii. Friendship } \\
\text { b. With patients' families or carers } \\
\text { c. With other HCPs } \\
\text { 5) Go above and beyond } \\
\text { a. Exceed patients' expectations } \\
\text { b. More than just a job issp: } \\
\text { c. Are present and accessible for patients } \\
\text { d. Explore other options or services } \\
\text { 6) Little things [sp] } \\
\text { a. Take an interest in the patient } \\
\text { b. Welcoming Have certain Attributes } \\
\text { c. Have certain attitudes } \\
\text { e. Make patients feel certain ways }\end{array}$ \\
\hline Template 4 & $\begin{array}{l}\text { 1) Care is individual } \\
\text { a. Patients are people } \\
\text { b. Patients are individuals } \\
\text { c. Doctors are individuals } \\
\text { 2)Caring doctors are competent } \\
\text { a. Implied competency } \\
\text { b. Perceived competency } \\
\text { c. Explicit Competency } \\
\text { 3) Communicate } \\
\text { a. Engage with patients }\end{array}$ \\
\hline
\end{tabular}




\begin{tabular}{|c|c|}
\hline & $\begin{array}{l}\text { b. Listen to patients } \\
\text { c. Ask appropriate questions } \\
\text { d. Act on patients' concerns } \\
\text { e. Engage with patients at their level } \\
\text { 4) Caring doctors form relationships } \\
\text { a. With patients } \\
\text { i. Ongoing or situational } \\
\text { ii. Quality } \\
\text { iii. Friendship } \\
\text { b. With patients' families or carers } \\
\text { c. With other HCPs } \\
\text { 5) Go above and beyond } \\
\text { a. Exceed patients' expectations } \\
\text { b. More than just a job } \\
\text { c. Are present and accessible for patients } \\
\text { d. Explore other options or services } \\
\text { 6) Patients have a role in caring } \\
\text { a. Take an interest in the patient } \\
\text { b. Welcoming } \\
\text { c. Have certain attitudes } \\
\text { d. Have certain Attributes } \\
\text { e. Make patients feel certain ways } \\
\text { c. SelfTworth } \\
\text { bersperiences }\end{array}$ \\
\hline Template 5 & $\begin{array}{l}\text { Overarching themes: } \\
\text { Complexity } \\
\text { Genuineness/Sincerity } \\
\text { 1) Care is individual [sp: } \\
\text { a. Patients are people } \\
\text { b. Patients are individuals } \\
\text { c. Doctors are people }\end{array}$ \\
\hline
\end{tabular}




\begin{tabular}{|c|}
\hline 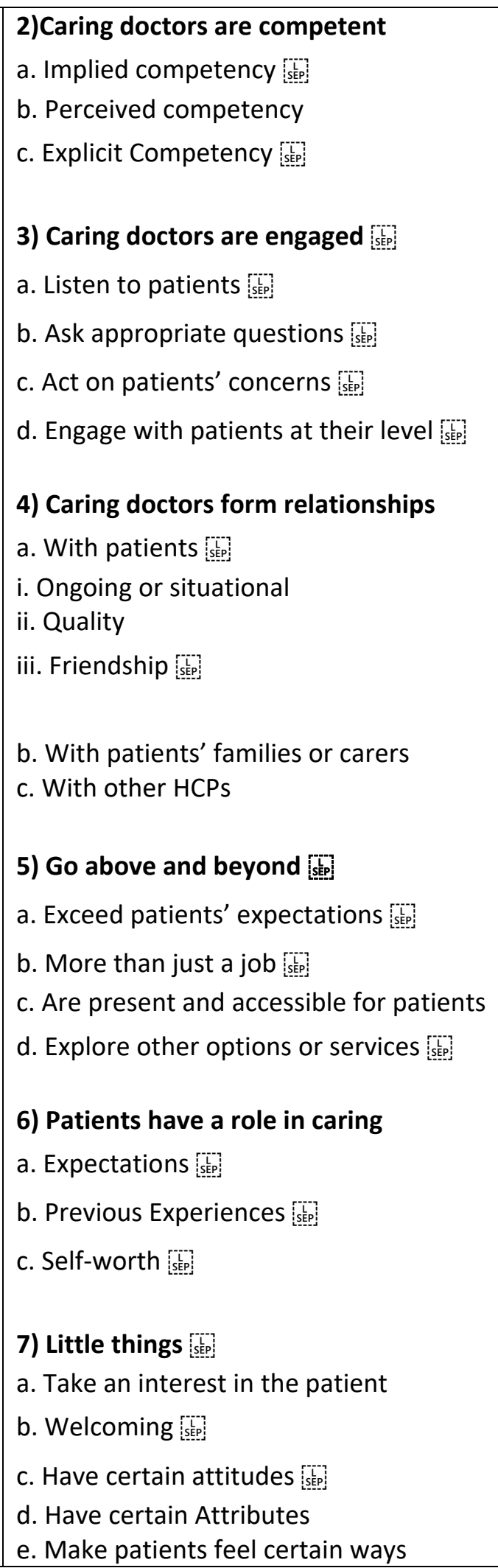 \\
\hline
\end{tabular}




\begin{tabular}{|c|c|}
\hline Template 6 & $\begin{array}{l}\text { Overarching themes: } \\
\text { Complexity } \\
\text { Genuineness/Sincerity/ Honesty } \\
\text { 1) Care is individual } \\
\text { a. Patients as people } \\
\text { b. Patients as individuals } \\
\text { c. Doctors as people } \\
\text { 2) Caring doctors are engaged } \\
\text { a. communication } \\
\text { b. relationships } \\
\text { 3) Caring doctors are competent } \\
\text { a. presumed competence } \\
\text { b. experienced competence } \\
\text { 4) Go above and beyond } \\
\text { 5) Little Things } \\
\text { 6) Influenced by factors beyond HCPs control }\end{array}$ \\
\hline Template 7 & $\begin{array}{l}\text { Overarching Themes } \\
\text { Caring is sincere } \\
\text { 1) Care is going above and beyond } \\
\text { a. competent } \\
\text { b. Little things } \\
\text { c. despite restraints } \\
\text { 2) Caring is engaged } \\
\text { a) Relationships } \\
\text { b) Communicate } \\
\text { 3) Caring is individual } \\
\text { a) Patients as people } \\
\text { b) Patients as individuals } \\
\text { c) Doctors as people }\end{array}$ \\
\hline Template 8 & $\begin{array}{l}\text { Overarching Theme } \\
\text { Caring is Genuine } \\
\text { 1) Individuality } \\
\text { 2) Engagement } \\
\text { 3) Little things that go above and beyond }\end{array}$ \\
\hline
\end{tabular}


$1 \quad$ Table 2

\begin{tabular}{|l|l|l|l|l|l|l|}
\hline Participant & Pseudonym & Sex & Age & Location & $\begin{array}{l}\text { Primary health } \\
\text { problem }\end{array}$ & Additional health problems \\
\hline A & Ben & M & 49 & Rural & Testicular cancer & $\begin{array}{l}\text { Back pain, umbilical hernia, } \\
\text { hypertension }\end{array}$ \\
\hline B & James & M & 70 & Rural & $\begin{array}{l}\text { Transient ischaemic } \\
\text { attack }\end{array}$ & Malignant melanoma \\
\hline C & John & M & 58 & Rural & $\begin{array}{l}\text { Type 2 Diabetes } \\
\text { Mellitus }\end{array}$ & $\begin{array}{l}\text { Transient ischaemic attack, } \\
\text { Osteoarthritis }\end{array}$ \\
\hline D & Frank & M & 58 & Rural & Generally felt well & Osteoarthritis \\
\hline E & Mary & F & 58 & Urban & Coeliac disease & - \\
\hline F & Alice & F & 55 & Rural & Hypokalaemia & Rheumatoid arthritis \\
\hline G & Sarah & F & 70 & Urban & Stroke & Arthritis, angina \\
\hline H & Helen & F & 68 & Urban & Ovarian cancer & $\begin{array}{l}\text { Depression, hypothyroidism, } \\
\text { appendicitis }\end{array}$ \\
\hline I & William & M & 68 & Urban & Bowel cancer & Atrial Fibrillation \\
\hline J & Sharon & F & 70 & Urban & $\begin{array}{l}\text { Cardiovascular } \\
\text { disease }\end{array}$ & Insomnia, Hodgkins Lymphoma \\
\hline 2 & & & & &
\end{tabular}

